\title{
PHYSICAL MODELLING OF GEOTECHNICAL STRUCTURES IN PORTS AND OFFSHORE
}

Lech Bałachowski, Prof.

Faculty of Civil and Environmental Engineering, Gdańsk University of Technology, Poland

\begin{abstract}
The physical modelling of subsoil behaviour and soil-structure interaction is essential for the proper design of offshore structures and port infrastructure. A brief introduction to such modelling of geoengineering problems is presented and some methods and experimental devices are described. The relationships between modelling scales are given. Some examples of penetration testing results in centrifuge and calibration chamber are presented. Prospects for physical modelling in geotechnics are also described.
\end{abstract}

Keywords: centrifuge, calibration chamber, CPT

\section{INTRODUCTION}

Interest in physical modelling of soil behaviour at high stress levels has considerably increased in recent decades. This is largely due to developments in offshore engineering, laboratory testing and in situ soil investigations. The main advantage of physical modelling is that it permits the parametric studies to be performed including the model geometry, different types or combinations of loading and soil conditions $[1,2,3]$. It is also possible to study the behaviour of the structure at different stages of construction process [4]. The reduced-scale models can be subjected to complex testing exposures including cyclic, dynamic or seismic forces $[5,6]$. Offshore engineering applications include: oil and gas platform foundations, wind farms, pile foundations, anchors and pipelines. In-situ soil investigations in marine civil engineering should be performed after preliminary soundings [7]. The calibration of new tools for in-situ investigations have become a major problem in geotechnics $[8,9]$. It is a question of great interest in the behaviour of non-standard materials from mineralogical point of view, cemented, containing high amount of fines or shells [10, 11]. It is also important when anthropogenic soils are used to improve the structure response or to reduce the liquefaction risk [12]. It can be solved in a series of tests in well defined and controlled boundary conditions, using a repeatable and homogeneous soil mass reconstituted in laboratory conditions, characterized by its void ratio, stress level and stress and strain history. Such samples can be also used in model tests thanks to the development of the modern experimental stations for physical modelling in geotechnics, like centrifuge facilities or calibration chamber devices. The soil models and soilstructure interaction under seismic loading can be also studied in shaking table model test [13] where the inertia forces can be taken into consideration.

Soil behaviour is highly non-linear concerning both stress and strain levels. It implies that the same stress and strain level is maintained in the reduced scale model and the prototype construction. This level of stress is varying considerably for different structures. It is about several $\mathrm{kPa}$ in case of cable or pipeline on the seabed, but it can reach a dozen of MPa under the platform foundation leg. In the first case a high dilatancy will be observed in shearing, while grain crushing and high soil contractancy will take place under high stress level. One should also remember that the soil deformability is also a function of stress level. Moreover, the degradation of the shear modulus with shear strain should be also taken into account when soil behaviour and soil-structure interaction is considered. It is thus important to maintain, in physical 
modelling in geotechnics, the same stress and strain level for the model and the prototype construction. The soil is a granular material with pores partially or completely filled with water. During cyclic, dynamic or seismic loading some water pressure is generated in the pores, which leads to effective stress reduction and in some cases may cause the soil liquefaction and failure of nearby structures. The question is important in harbour design [12] and it needs careful determination of environmental wave and wind loading on offshore structures [14].

\section{SIMILITUDE CONDITIONS IN PHYSICAL MODELLING}

Let us consider the similitude conditions between a model and its prototype. Let us assume a model of the dimension $B$ and its prototype of the dimension $b$. The scale factor between the two variables can be defined as the geometrical scale $x^{*}$ :

$$
x^{*}=\frac{B}{b}=\frac{1}{n}
$$

where

$n$ - modelling scale.

The other modelling scales can be defined as:

- stress scale $\sigma^{*}=\frac{\sigma_{M}}{\sigma_{P}}$

- gravity scale $g^{*}=\frac{g_{M}}{g_{P}}$

- volumetric density scale $\rho^{*}=\frac{\rho_{M}}{\rho_{P}}$

where indexes $M$ and $P$ denote the model and the prototype, respectively.

The equilibrium condition of continuum mechanics for static loading can be written as:

$$
\sum_{j=1.3} \frac{\partial \sigma_{\ddot{j}}}{\partial x_{j}}+\rho \cdot g_{i}=0
$$

Dimensional analysis of Eq. 5 ? needs the following equation to be satisfied:

$$
\sigma^{*}=x^{*} \cdot g^{*} \cdot \rho^{*}
$$

If the same material is used for the model and the prototype $\left(\rho^{*}=1\right)$, the same stress level is applied $\left(\sigma^{*}=1\right)$ to maintain the soil rheology, and the model $n$-times smaller than the prototype is used, the gravity should be $n$-times increased to respect the similitude condition (Eq. 3). In this case the gravity scale should be $n$-times higher for the model:
The stress level can be increased either in centrifuge tests or calibration chamber. In centrifuge model tests, the stress level increase is realized with the use of the soil container flying in a horizontal plane at constant radial velocity. In case of calibration chamber the stress is applied by the membranes around the soil specimen. The scale factors for the interpretation of centrifuge tests are summarized in Tab. 1, where time scale factors depends on the phenomena to be studied. One should notice that in the small-scale model which is geometrically identical to the prototype, the homologous points are subjected to the same stresses and strains. Thus it is possible to include stress and strain dependence of soil characteristics and to properly describe the soil-structure interaction. More detailed information concerning the scale factors in centrifuge modelling can be found in $[15,16]$. In calibration chamber tests the response of real size probes for in-situ testing like CPTU, DMT, pressure meter, cone pressure meter and others, can be studied in well-defined boundary conditions [10]. In this case no scale factor applies and the results can be transfer directly to the prototype behaviour after the examination of the influence of boundary effects.

When the tests on so-called small models at $1 \mathrm{~g}$ acceleration are performed the strict similitude conditions are not fulfilled and some additional detailed analyses of the influence of size and scale effects should be done for the applied models. A possible distortion in the similitude conditions arises if deformations appear in the soil mass or a shear band forms in the soil-structure interface. When the size of the model is getting closer to the mean grain size an eventual grain size effect should be verified. The correct interpretation of such tests needs some correction factors to be applied [17].

Important advantage of physical modelling is that the tests are performed in reconstituted homogeneous soil mass with well-known parameters established in extensive laboratory tests. The soil can be prepared to meet a certain range of parameters including the stress history of soil deposit. It is thus possible to calibrate the response measured in model tests to soil characteristics and to establish some correlations for design.

Tab. 1 Scale factors in centrifuge tests

\begin{tabular}{|c|c|c|}
\hline Parameter & Prototype & Model \\
\hline length & 1 & $n$ \\
\hline surface & 1 & $n^{2}$ \\
\hline volume & 1 & $n^{3}$ \\
\hline mass & 1 & $n^{3}$ \\
\hline time (inertia) & 1 & $n$ \\
\hline acceleration & 1 & $1 / n$ \\
\hline stress & 1 & 1 \\
\hline strain & 1 & $n$ \\
\hline displacement & 1 & $n^{2}$ \\
\hline force & & 1 \\
\hline
\end{tabular}

$$
g^{*}=\frac{1}{x^{*}}=n
$$




\section{GEOTECHNICAL CENTRIFUGE}

Numerous experimental devices were constructed all over the world to study physical modelling in geotechnics. The first geotechnical centrifuge was constructed in the former URSS, mainly for military purposes [18]. A view of the recent centrifuge used in Ifsttar laboratories near Nantes is shown in Fig.1. It is a beam centrifuge where the container with the model of the mass up to $2000 \mathrm{~kg}$ is placed in the swinging basket of the machine. Different stages of construction works or combinations of loads can be modelled in-flight during the experiment. Offshore engineering is one of the principal domains for this modelling [20,21,22]. The effect of stress level on the cone resistance mobilized during CPT penetration test in centrifuge is given in Fig. 2. Here, a mini-cone model of $12 \mathrm{~mm}$ in diameter is penetrating dense quartz sand medium at the acceleration level of $60 \mathrm{~g}$ at $100 \mathrm{~g}$. In this case the cone resistance with vertical effective stress in the subsoil up to $400 \mathrm{kPa}$ can be studied, which corresponds roughly to the penetration depth of $40 \mathrm{~m}$ below seabed. New probes for in-situ testing in offshore engineering like ball-cone, $t$-bar, mini-pressure meter were extensively calibrated in centrifuge tests.

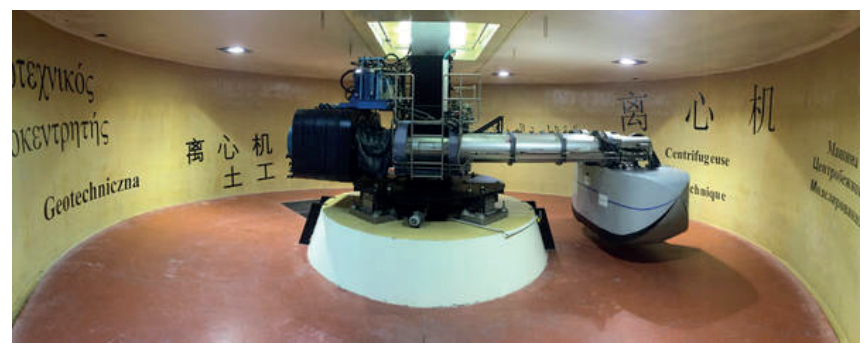

Fig. 1. Geotechnical centrifuge at Ifsttar [19].

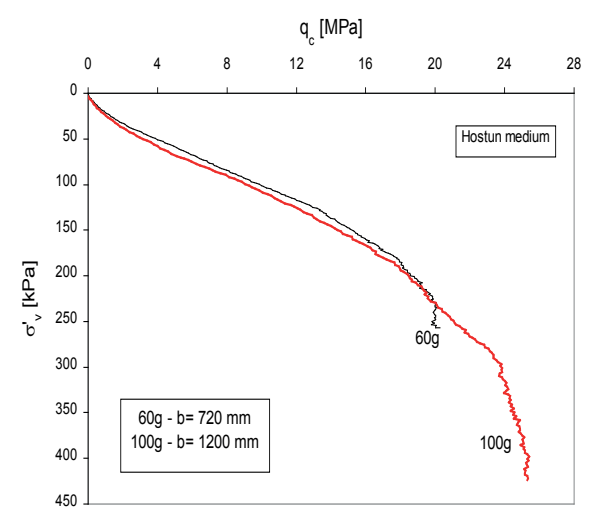

Fig. 2 Set of CPT results for Hostun dense quartz sand medium in centrifuge [23].

\section{CALIBRATION CHAMBER}

Calibration chamber is another example of large experimental device for physical modelling [10]. Numerous chambers has been constructed in Italy, USA, Great Britain, China and Japan [10,23]. Such device was also designed and built at the Geotechnical Laboratory of GUT ( = Gdańsk University of Technology? ), which can house soil sample of $53 \mathrm{~cm}$ in diameter and $100 \mathrm{~cm}$ high [24]. With self-reacting design, the chamber is placed within the rigid steel frame (Fig. 3). Hydraulic insertion cylinder with load cell and sand storage bin for stationary sand spreader are mounted on the frame. It is double wall chamber with independent pressure control in internal and external chambers, which enables complex boundary conditions to be applied with pneumatic control system (Fig. 4). Top and bottom membranes and the lateral cells are filled with water. Four air-water columns and pressure transducers are fixed on the control panel. Volumetric changes in the top and bottom membranes and the internal chamber are measured with the position of the floating element in air-water columns equipped with BTL2 micropulse transducers. Four applied pressures are controlled with pneumatic system. The central hole in the bottom plate permits to make tests with model piles which transverse the chamber entirely.

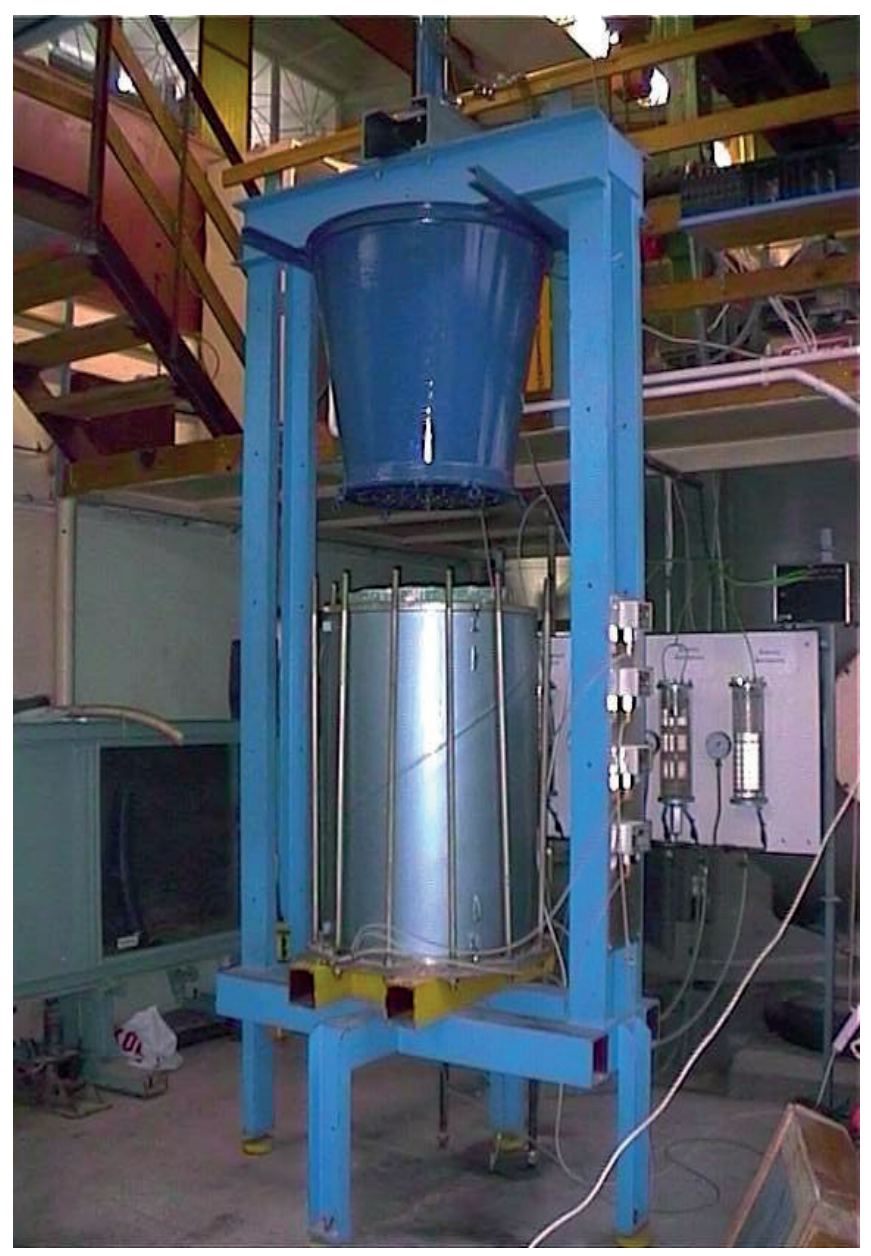

Fig. 3 Calibration chamber at GUT [24] 


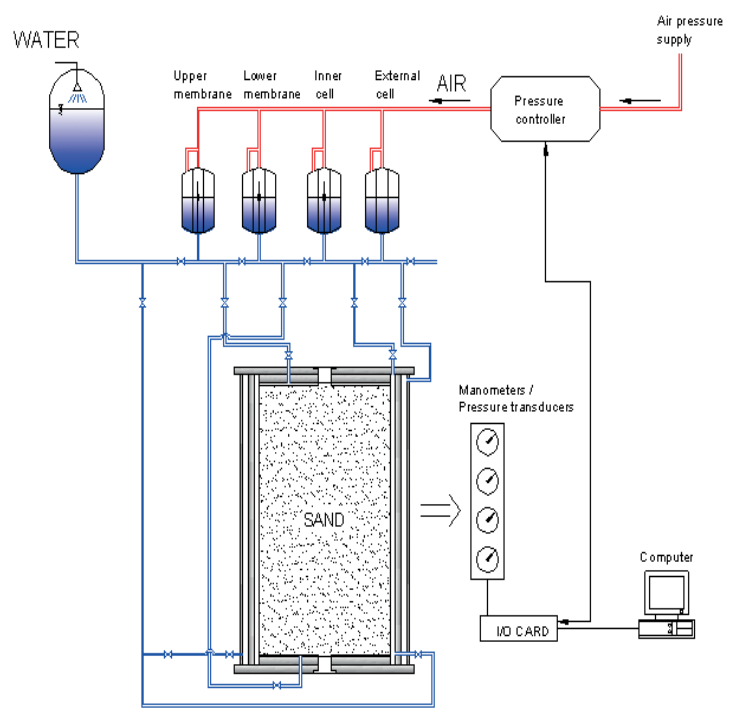

Fig. 4 Scheme of the calibration chamber set-up with control system [24]

The reconstituted soil mass is not infinite, so the influence of boundary conditions around the specimen in calibration chamber should be evaluated. Five types of boundary conditions expressed in stresses and strains can be applied (Tab. 2). Special BC5 condition is intended to simulate infinite soil mass with a lateral stiffness corresponding to that of surrounding soil.

Tabl. 2 Boundary conditions to be applied

\begin{tabular}{|c|c|c|}
\hline Boundary conditions & Horizontal & Vertical \\
\hline BC1 & $\sigma_{h}=$ const & $\varepsilon_{v}=$ const \\
\hline BC2 & $\varepsilon_{h}=0$ & $\varepsilon_{v}=0$ \\
\hline BC3 & $\varepsilon_{h}=0$ & $\varepsilon_{v}=$ const \\
\hline BC4 & $\sigma_{h}=$ const & $\sigma_{v}=0$ \\
\hline BC5 & $\begin{array}{c}\text { lateral stiffness } \\
k=\text { const }\end{array}$ & $\sigma_{v}=$ const \\
\hline
\end{tabular}

The main application of calibration chamber tests is a verification of in-situ test response in well-defined soil conditions, applied stress level and boundary conditions. Some local correlations concerning the interpretation of in-situ tests are developed including the effect of soil mineralogy, compressibility, density and stress level [10]. The mobilization of cone resistance in Lubiatowo dense sand at different vertical stress level applied to the chamber is given in Fig.5. Local correlation for the interpretation of CPTU tests in quartz sands on the Baltic coast was proposed on the basis of a series of calibration chamber tests and in-situ investigations in sands deposit on the Baltic coast [25]. Other applications of calibration chamber are related to analyses of pile behaviour [1], installation effects and plate loading tests. The device can also operate as a large triaxial apparatus when large grain material is used.

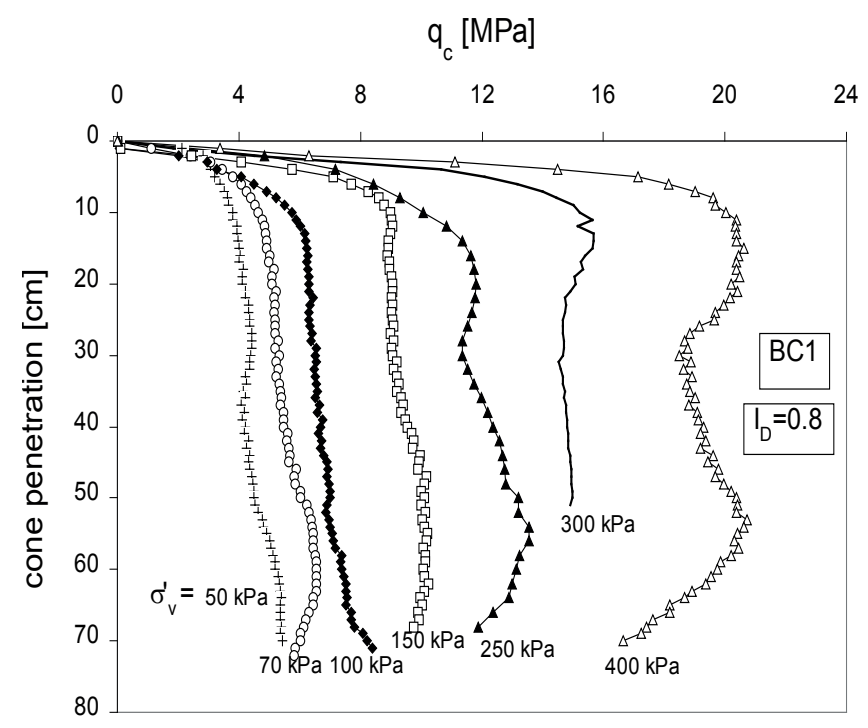

Fig. 5. Cone resistance mobilization in Lubiatowo dense sand at $B C 1$ condition [25]

\section{PROSPECTS AND CONCLUSIONS}

The experimental devices for physical modelling in geotechnics offer the possibility of wide range parametric studies of complex foundations in offshore and port structures. Such study is substantially cheaper, effective and faster than full scale experiment, often impossible to perform. The latter, rare and expensive tests are however used to validate the obtained results and to verify chosen assumption. In physical modelling one can thus consider more options concerning soil and foundation model geometry and to check more loading conditions schemes. The most advanced laboratories are even able to combine the advantages of two experimental devices, i.e. the calibration chamber can be placed in the swinging basket of centrifuge to study the effect of boundary conditions or the shaking table can be used to apply seismic exposure to the model in centrifuge test.

New advances in physical modelling in geotechnics are related to the development of in-flight robotics, instrumentation and recording the results. One should, however, consider high complexity of problems to be studied. If the behaviour of the superstructure can be relatively easily modelled the main difficulties are related to the soil response. Stress and strain level effects on the soil characteristics together with mobilization and accumulation of water pressures in a granular material subjected to cyclic or dynamic loading should be analyzed [26]. The problem is how to consider together the physical modelling of the structure, subsoil and their interaction. If a shallow foundation is considered [27] the problem is less complex than in case of deep foundation embedded in the subsoil where comprehensive nonlinear soil-structure interaction should be taken into account [27]. Then a simplified physical modelling at $1 \mathrm{~g}$ acceleration could be only the first attempt. Parallel physical modelling and 
numerical analysis could be very useful and promising to fill the gap. They should be supported by detailed laboratory analyses of soil behaviour and soil-structure interaction under dynamic or cyclic loading to identify and better describe the governing mechanisms.

\section{REFERENCES}

1. Foray, P., Bałachowski, L., Colliat, J -L.? : Bearing capacity of model piles driven into dense over-consolidated sand. Canadian Geotechnical Journal, 1998, 35(2), pp. 374-385, 10.1139/t97-082.

2. Tsuha, C. D. H. C., Aoki, N., Rault, G., Thorel, L., \& Garnier, J. Evaluation of the efficiencies of helical anchor plates in sand by centrifuge model tests. Canadian Geotechnical Journal, 2012, 49(9), pp. 1102-1114.

3. Fioravante, V. : Load transfer from a raft to a pile with an interposed layer. Géotechnique, 2011, 61(2), pp.121-132.

4. Le Kouby, A., Dupla, J. C., Canou, J., \& Francis, R.: The effects of installation order on the response of a pile group in silica sand. Soils and Foundations, 2016, 56(2), pp.174-188.

5. Falborski T., Jankowski R.: Polymeric Bearings - A New Base Isolation System to Reduce Structural Damage during Earthquakes. $10^{\text {th }}$ International Conference on Damage Assessment of Structures (DAMAS), 2013. http://www. scientific.net/KEM.569-570.143

6. Jankowski R.: Experimental study on earthquake-induced pounding between structural elements made of different building materials. Earthquake Engineering \& Structural Dynamics, 2010, Vol. 39, Issue 3, pp. 343-354, DOI: 10.1002/eqe.941

7. Kozaczka E., Grelowska G., Kozaczka S.: Images of the Seabed of the Gulf of Gdansk Obtained by Means of the Parametric Sonar. Acta Physica Polonica A., 2010,Vol. 118, No.1, pp. 91-94

8. Grelowska G., Kozaczka E.: Sounding of Layered Marine Bottom - Model Investigations. Acta Physica Polonica A., 2010,Vol. 118, No.1, pp. 66-70.

9. Grelowska G., Kozaczka E., Nowicki A., Kozaczka S.: Investigation of Transmit and Receive Characteristics of Laboratory Model for the Parametric Echosounder. Acta Physica Polonica A., 2013,Vol. 123, No.6 , pp. 1094-1097.

10. Ghionna, V.N., Jamiolkowski, M. : A critical appraisal of calibration chamber testing in sands. Proceedings of the $1^{\text {st }}$ International Conference on Calibration Chamber Testing, Clarkson Univ., Potsdam, USA, 1991. Edited by A.-B. Huang, pp. 13-37.
11. Dijkstra, J., Gaudin, C., \& White, D. J. : Comparison of failure modes below footings on carbonate and silica sands. International Journal of Physical Modelling in Geotechnics , 2013, 13 (1).

12. Hazarika, H., Kohama, E. and Sugano, T.: Underwater shake table on waterfront structures protected with tire chips cushion. J. Geotechnical and Geoenvironmental Engineering, (ASCE), 2008, Vol. 134, No.12.

13. Mahmoud S., Abd-Elhameed A., Mahmoud S., Jankowski R.: Earthquake-induced pounding between equal height multi-storey buildings considering soil-structure interaction. Bulletin of Earthquake Engineering, 2013, Vol. 11, Issue 4 , pp.1021-1048. http://link.springer.com/10.1007/ s10518-012-9411-6

14. Dymarski C., Dymarski P.: Developing Methodology for Model Tests of Floating Platforms in Low-Depth Towing Tank. Archives of Civil and Mechanical Engineering, 2016, Vol. 16, Issue 1, pp. 159-167

15. Garnier, J., Gaudin, C., Springman, S. M., Culligan, P. J., Goodings, D., Konig, D., ... \& Thorel, L. : Catalogue of scaling laws and similitude questions in geotechnical centrifuge modelling. International Journal of Physical Modelling in Geotechnics, 2007, 7(3), 1.

16. Konkol, J. : Derivation of the scaling laws used in geotechnical centrifuge modelling-application of dimensional analysis and Buckingham $\Pi$ theorem. Technical Sciences/ University of Warmia and Mazury, Olsztyn , 2014.

17. Foray, P., Bałachowski, L., \& Rault, G. : Scale effect in shaft friction due to the localization of deformations. In Proceedings of the international conference on centrifuge ,Tokyo, 1998, Vol. 98, pp. 211-216.

18. Madabhushi, G. : Centrifuge Modelling for Civil Engineers. CRC Press.

19, 2015, http://eurofuge2016.ifsttar.fr

20. Bayton, S.M., Black, J.A. : The effect of soil density on offshore wind turbine monopile foundation performance. Proc. of $3^{\text {rd }}$ European Conference on Physical Modelling in Geotechnics, Eurofuge 2016, Nantes, pp. 239-244.

21. Loli, M., Kassas, K. \& Anastasopoulos, I. : Centrifuge testing of a hybrid foundation for offshore wind turbines: experimental technique and preliminary results. Proc. of $3^{\text {rd }}$ European Conference on Physical Modelling in Geotechnics, Eurofuge 2016, Nantes, pp. 263-268.

22. Blanc, M., Thorel, L., Isorna, R., Dano, C., Kotronis, P., Philippe, M. : Centrifuge investigation of axial cyclic behaviour of a single pile used for the foundation of a jacket 
type offshore wind turbine. Proc. Frontiers in offshore geotechnics, ISFOG 2015, Oslo, Norway, CRC Press, pp. 521-526.

23. Bałachowski, L. : Size effect in centrifuge cone penetration tests. Archives of Hydro-Engineering and Environmental Mechanics, 2007, 54(3), pp. 161-181.

24. Bałachowski, L. Physical modelling in sands in a wide range of stress level: Application to the calibration of CPTU and DMT tests. Wydawnictwo Politechniki Gdańskiej, Gdańsk 2008.

25. Bałachowski, L. : Penetration resistance of Lubiatowo sand in calibration chamber tests. Archives of HydroEngineering and Environmental Mechanics, 2006, 53(4), pp. 311-329.

26. Mortara, G., Mangiola, A., \& Ghionna, V. N. : Cyclic shear stress degradation and post-cyclic behaviour from sandsteel interface direct shear tests. Canadian Geotechnical Journal, 2007, 44(7), pp. 739-752.

27. Dymarski C., Dymarski P., Żywicki J.: Design and strength calculations of the tripod support structure for offshore power plant. Polish Maritime Research , 2015,Vol. 22, No.1(85), pp. 36-46.

\section{CONTACT WITH THE AUTHOR}

\section{Lech Bałachowski}

Faculty of Civil and Environmental Engineering, Gdańsk University of Technology

\section{Poland}

